\title{
MOBILIZAÇÃO DO SOLO, EROSÃO E PRODUTIVIDADE DE MILHO E FEIJÃO EM UM REGOSSOLO NO AGRESTE PERNAMBUCANO'
}

\author{
ADEMAR BARROS DA SILVA ${ }^{2}$, MAURO RESENDE ${ }^{3}$, ANTONIO RAIMUNDO DE SOUSA ${ }^{4}$ e ELIAS MARGOLIS ${ }^{5}$
}

RESUMO - Este estudo foi conduzido no município de Caruaru (PE), no período de 1970 a 1990, em um Regossolo eutrófico com $12 \%$ de declividade, para avaliar o efeito de diferentes graus de mobilização sobre as perdas de solo e água e sobre a produtividade de milho (Zea mays L.) e feijão (Phaseolus vulgaris L.), em condições de chuva natural. Os dados foram coletados em quatro talhões de $1.000 \mathrm{~m}^{2}$, equipados com coletores de material erosado, compreendendo os seguintes tratamentos: enxada (manual), aração e gradagem, duas arações e gradagem, e gradagem. Comparando as perdas médias anuais de solo e água, verificou-se que a maior intensidade de mobilização provocou as maiores perdas, mas que, de modo geral, foram muito baixas, fato atribuído às quantidades de cascalho e areia grossa existentes no perfil do solo, por reduzirem o impacto das gotas de chuva e aumentarem a permeabilidade do solo. Além do mais, os tratamentos mais mobilizados, por colocarem as camadas mais ricas em nutrientes a profundidades maiores, facilitando a absorção deles, proporcionaram as maiores produtividades médias de milho e feijão, com destaque para o milho. Houve boa correlação da produtividade média do milho com os teores médios de P extraível, nas profundidades de 9 a $14 \mathrm{~cm}$, de 10 a $19 \mathrm{~cm}$ e de 14 a $22 \mathrm{~cm}$.

Termos para indexação: Zea mays, Phaseolus vulgaris, métodos de preparo do solo, escoamento superficial, perda de solo, perda de água.

\section{SOIL MOBILIZATION, EROSION AND CORN AND BEAN YIELDS IN A REGOSOL ON THE PERNAMBUCO STATE DRY AREA}

\begin{abstract}
This study was conducted in Caruaru County, PE, Brazil, from 1970 to 1990, in an eutrophic Regosol 12\% slope, to evaluate different soil tillage methods on soil and water losses and corn (Zea mays L.) and bean (Phaseolus vulgaris L.) productivity under natural rainfall conditions. Data were obtained from four $1,000 \mathrm{~m}^{2}$ experimental plots equiped to collect eroded material from the following treatments: hoe (manual), plow and harrow, double plow and harrow, and only harrow. The mean annual soil and water losses was higher with plowing twice and harrowing and with plowing and harrowing treatments, but, in general, the losses were low in all treatments. This fact was attributed to the large amounts of gravel and coarse sand in the soil profile by reducing direct impact of rain drops and increasing permeability. The more intensive soil tillage methods, by placing richer layer in nutrients deeper, where more water is available, increase nutrient absorption resulting in higher productivity specially for corn. There was significant correlation between corn productivity and average $\mathrm{P}$ content from 9 to $14 \mathrm{~cm}, 10$ to $19 \mathrm{~cm}$ and 14 to $22 \mathrm{~cm}$ depths.
\end{abstract}

Index terms: Zea mays, Phaseolus vulgaris, soil tillage methods, runoff, soil loss, water loss.

${ }^{1}$ Aceito para publicação em 4 de junho de 1998.

${ }^{2}$ Eng. Agr., M.Sc., Embrapa-Centro Nacional de Pesquisa de Solos (CNPS-UEP-Recife), Rua Antonio Falcão, 402, Boa Viagem, CEP 51020-240 Recife, PE. E-mail: fbarreto@embrapacnpsuep.com.br

${ }^{3}$ Eng. Agr., Ph.D., Dep. de Solos, Universidade Federal de Viçosa, CEP 36570-000 Viçosa, MG.

${ }^{4}$ Eng. Agr., D.Sc., IPA, Av. Gal. San Martin, 1371, Bonji, CEP 50761-000 Recife, PE.

${ }^{5}$ Eng. Agr., Ph.D., Dep. de Agronomia, UFRPE, CEP 50000-000 Recife, PE.

\section{INTRODUÇÃO}

Sob o ponto de vista agronômico, o solo constitui o substrato para qualquer atividade agrossilvipastoril e, dependendo do manejo ao qual é submetido, é passível de degradação ou melhoramento em sua capacidade produtiva. Esse recurso, inserido em um ecossistema, está sujeito às variações dos demais componentes, em especial clima, 
vegetação e sistema hídrico (Baruqui \& Fernandes, 1985).

A erosão hídrica também faz parte do ecossistema e está relacionada com o escoamento superficial, que é a fase do ciclo hidrológico correspondente ao conjunto das águas que sob a ação da gravidade, se movimenta na superfície do solo. São vários os fatores que contribuem com o escoamento superficial. De acordo com Vilella \& Mattos (1975), eles podem ser de natureza agroclimática, relacionados à precipitação e de natureza fisiográfica, ligados às características físicas da área. Nos fatores agroclimáticos estão incluídos quantidade, intensidade e duração da precipitação (Cantalice \& Margolis, 1993; Albuquerque et al., 1994); sua distribuição temporal e espacial (Wischmeier \& Smith, 1978); condições precedentes de umidade; interceptação pela cobertura vegetal (Seganfredo et al., 1997) e também a evapotranspiração. Com relação aos fatores fisiográficos, podem ser destacados: a declividade e comprimento de rampa (Bertoni et al., 1975; Bertol et al., 1997), forma do terreno (Resende, 1985), a classe de solo e tipos de cultivo.

A erosão causada pelo escoamento superficial não é a mesma em todos os solos. A condição física, ao conferir maior ou menor resistência à ação das águas, tipifica o comportamento de cada classe de solo exposto a condições semelhantes de relevo, chuva e cobertura vegetal (Bertoni \& Lombardi Neto, 1985). A textura do solo é um dos fatores que influem na maior ou menor quantidade de solo arrastado pelo escoamento superficial. Em solo arenoso, onde predominam macroporos, durante uma chuva de baixa intensidade, a água pode ser toda absorvida, não havendo, portanto, grandes problemas relacionados com a erosão.

A profundidade do solo e as características do subsolo contribuem para a capacidade de armazenamento da água. Um solo arenoso superficialmente, com subsolo de textura média, deverá absorver mais água que esse mesmo solo com um subsolo mais compacto e pouco permeável.

A velocidade de infiltração e o armazenamento da água no solo podem também sofrer influência das práticas de manejo adotadas. Os sistemas de preparo que reduzem o número de operações com implementos de discos provocam menor pulveriza- ção do solo superficialmente, reduzem a formação de camadas compactadas e aumentam a capacidade de infiltração e a quantidade de água armazenada no solo (Oliveira et al., 1990).

Os sistemas de preparo do solo existentes afetam distintamente o escoamento superficial e conseqüentemente o processo erosivo, por causa das diferentes intensidades de movimentação que provocam, conforme foi observado por Margolis \& Mello Netto (1977) no Agreste de Pernambuco.

Entre os solos mais cultivados no Agreste pernambucano estão os Regossolos, que ocupam aproximadamente $38 \%$ da área (Silva, 1986). São solos jovens, medianamente profundos, de textura arenosa e às vezes cascalhenta, em todo o perfil, baixa retenção de umidade, baixos valores de capacidade de troca catiônica (CTC) e baixos teores de matéria orgânica (Brasil, 1972). Esses solos apresentam elevado índice de utilização, com métodos tradicionais de cultivo e ausência de práticas conservacionistas. Para o plantio, eles são preparados antes mesmo do período chuvoso, de diferentes maneiras, utilizando-se como implementos enxada (manual), arado de aiveca (tração animal), arado e grade de discos (tração mecânica).

Sabe-se que de modo geral, o preparo intensivo do solo, principalmente sem o uso de práticas conservacionistas, favorece as perdas de solo e água por erosão, comprometendo sua capacidade para a produção agrícola, além de outros problemas causados ao ambiente.

O presente trabalho teve como objetivo estudar o efeito do preparo do solo sobre as perdas por erosão e sobre a produtividade de milho e feijão, sob chuva natural.

\section{MATERIAL E MÉTODOS}

O experimento foi conduzido no Campo Experimental de Caruaru da Empresa Pernambucana de Pesquisa Agropecuária-IPA, num Regossolo eutrófico, com declividade média de $12 \%$. Algumas características físicas do perfil podem ser observadas na Tabela 1.

Segundo a sistemática de Köppen (Brasil, 1973), a dominância climática da região estudada é do tipo BSs'h', que se caracteriza por ser muito quente, semi-árido, com período chuvoso correspondendo ao outono. As médias térmicas anuais estão em torno de $24^{\circ} \mathrm{C}$ e as do mês mais 
frio, entre $20^{\circ}$ e $22^{\circ} \mathrm{C}$. De acordo com os dados registrados no Campo Experimental de Caruaru, a precipitação pluvial média anual é de $668 \mathrm{~mm}$ (período 1953/88), com o maior volume de chuvas concentrado nos meses de março a julho. As atividades agrícolas desenvolvem-se, de modo geral, nos meses de fevereiro a setembro.

O trabalho foi conduzido em condições de chuva natural durante 21 anos (1970/90), em quatro talhões de $1.000 \mathrm{~m}^{2}(20 \times 50 \mathrm{~m})$ cada um (limitados superior e lateralmente por camalhões de terra com cerca de $0,4 \mathrm{~m}$ de altura), equipados com conjuntos coletores de alvenaria (para medir as perdas de solo e água), constituídos de uma soleira conjugada a três tanques construídos em série e interligados com calhas divisoras de janelas tipo "Geib" (Margolis \& Albuquerque, 1971), compreendendo os seguintes tratamentos: enxada (EN); aração e gradagem (AG); duas arações e gradagem (2AG) (a primeira aração feita nas primeiras chuvas, e a segunda feita por ocasião do preparo do solo dos demais tratamentos); e gradagem (GR). Foram utilizados arado com três discos e grade com 22 discos, ambos com tração mecânica. O preparo do solo e o plantio das culturas foram feitos anualmente em contorno. $\mathrm{O}$ milho foi plantado isolado (espaçamento $1,0 \mathrm{~m} \mathrm{x} \mathrm{0,4} \mathrm{m}$ com duas plantas/cova) e adubado com 90, 100 e $90 \mathrm{~kg} / \mathrm{ha} \mathrm{de} \mathrm{N,}$ $\mathrm{P}_{2} \mathrm{O}_{5}$ e $\mathrm{K}_{2} \mathrm{O}$, respectivamente, no período $1970 / 78$ e sem adubação em 1979. No período 1980/86 as culturas utilizadas foram milho (espaçamento $1,5 \mathrm{~m}$ x $0,8 \mathrm{~m}$ com duas plantas/cova) e feijão (espaçamento $0,5 \mathrm{~m} \times 0,2 \mathrm{~m}$ com uma planta /cova) consorciados, sem adubação. Em 1987 utilizou-se a cultura de feijão-de-corda (Vigna unguiculata (L.) Walp.) em espaçamento de 0,6 m x 0,4 $\mathrm{m}$ com duas plantas/cova, sem adubação, e, no período 1988/90, tomate industrial (Lycopersicum esculentum Mill) em espaçamento de $1,2 \mathrm{~m}$ x 0,3 $\mathrm{m}$ com uma planta/cova, adubado com 60,40 e $80 \mathrm{~kg} /$ ha de $\mathrm{N}, \mathrm{P}_{2} \mathrm{O}_{5}$ e $\mathrm{K}_{2} \mathrm{O}$, respectivamente.

As determinações de campo e de laboratório, para obtenção dos valores totais de perdas de solo e água na enxurrada, foram feitas de acordo com método proposto por Bertoni (1949) e Cogo (1978), considerando-se cada ta- lhão experimental como tratamento e os anos como repetições.

Os valores médios foram calculados, estabelecendo-se uma proporção entre as perdas reais verificadas anualmente com as chuvas ocorridas e aquelas perdas que seriam esperadas para uma chuva correspondente ao total médio do período (Marques et al., 1961), e dividindo-se o somatório dessas perdas ponderadas pelo número de anos de realização do trabalho (21).

Para o estudo da produção de milho e feijão, considerou-se a área total de cada tratamento e o período de 1977 a 1986, expressando-se os valores em $\mathrm{kg} / \mathrm{ha}$.

Visando também estudar a distribuição dos nutrientes em profundidade e em função do manejo do solo, foram coletadas (no ano de 1985) amostras de solo em camadas delgadas (com volume determinado de 1,2 litro) em cada tratamento, com duas repetições, nas seguintes profundidades (cm): 1-2; 2-3; 3-4; 4-5; 5-6; 6-7; 7-8; 8-9; 9-10; $10-12 ; 12-14 ; 14-16 ; 16-19 ; 19-22 ; 22-25 ; 25-30 ; 30-40$. As análises químicas foram feitas segundo método proposto por Defelipo \& Ribeiro (1981).

\section{RESULTADOS E DISCUSSÃO}

As perdas de solo e água ocorridas no período 1970/90 (Tabela 2) foram variáveis ao longo dos anos, em virtude principalmente da irregularidade na distribuição das chuvas. As maiores perdas de solo e água ocorreram nos tratamentos que receberam mobilização mais intensa, ou seja, $2 \mathrm{AG}$ (duas arações e gradagem) e AG (aração e gradagem), proporcionando aumento nas perdas de solo 7,4 e 4,2 vezes e de água 2,6 e 2,5 vezes, respectivamente, quando comparados com o tratamento EN (enxada) considerado tradicional. Esses dados confirmam os resultados obtidos por Duley \& Russel (1942), Browning \& Norton (1947), Marques \& Bertoni (1961), Margolis \& Mello Netto (1977), Biscaia (1978) e Freitas et al.

TABELA 1. Algumas características físicas do Regossolo eutrófico em Caruaru, PE.

\begin{tabular}{|c|c|c|c|c|c|c|c|c|c|c|c|}
\hline \multirow[t]{2}{*}{ Horizonte } & \multirow[t]{2}{*}{ Profundidade } & \multicolumn{5}{|c|}{ Granulometria $^{1}$} & \multicolumn{2}{|c|}{ Densidade } & \multicolumn{2}{|c|}{ Umidade } & \multirow{2}{*}{$\begin{array}{c}\text { Água } \\
\text { disponível }\end{array}$} \\
\hline & & $\mathrm{cs}$ & ag & af & $\mathrm{s}$ & $\mathrm{r}$ & Solo & Partículas & $-33 \mathrm{kPa}$ & $-1.500 \mathrm{kPa}$ & \\
\hline & ---- $(\mathrm{cm})$----- & ---- & - & $(\%)$ & - & --- & ----- & $\left.\mathrm{cm}^{-3}\right)$----- & 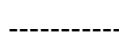 & $---(\%)$ & $\ldots$ \\
\hline A & $0-35$ & 14 & 54 & 33 & 5 & 8 & 1,41 & 2,51 & 7,82 & 3,19 & 4,63 \\
\hline $\mathrm{C}$ & $35-80$ & 18 & 50 & 30 & 9 & 11 & 1,50 & 2,45 & 7,74 & 3,56 & 4,18 \\
\hline
\end{tabular}

${ }^{1}$ cs: cascalho; ag: areia grossa; af: areia fina; s: silte; r: argila. 
TABELA 2. Perdas de solo em t/ha e água $\mathrm{em} \mathrm{mm}$ (anual, total acumulado, média ponderada e percentagem de chuva escorrida) por erosão com chuva natural, total de chuva (anual e que provocou escoamento superficial) em um Regossolo eutrófico sob cultivo, com 12\% de declividade, em diferentes sistemas de mobilização no Agreste de Pernambuco.

\begin{tabular}{|c|c|c|c|c|c|c|}
\hline \multirow[t]{2}{*}{ Anos } & \multicolumn{4}{|c|}{ Tratamento } & \multicolumn{2}{|c|}{ Chuva (mm) } \\
\hline & Enxada & $\begin{array}{c}\text { Aração } \\
\text { e gradagem }\end{array}$ & $\begin{array}{l}\text { Duas arações } \\
\text { e gradagem }\end{array}$ & Gradagem & Total & Provocou ES ${ }^{1}$ \\
\hline 1970 Solo & 0,193 & 0,434 & 0,101 & 0,154 & 712,0 & 647,3 \\
\hline Água & 16,7 & 30,0 & 4,5 & 13,6 & & \\
\hline 1971 Solo & 0,008 & 0,038 & 0,261 & 0,012 & 620,1 & 565,0 \\
\hline Água & 2,8 & 6,9 & 11,3 & 3,5 & & \\
\hline 1972 Solo & 0,424 & 0,224 & 0,939 & 0,353 & 705,0 & 640,9 \\
\hline Água & 18,7 & 21,4 & 28,7 & 25,6 & & \\
\hline 1973 Solo & 0,168 & 0,068 & 0,014 & 0,017 & 665,7 & 600,7 \\
\hline Água & 6,8 & 5,4 & 3,0 & 4,9 & & \\
\hline 1974 Solo & 0,622 & 0,497 & 0,407 & 0,179 & 934,0 & 849,1 \\
\hline Água & 17,4 & 16,8 & 11,9 & 12,1 & & \\
\hline 1975 Solo & 0,048 & 1,109 & 1,229 & 0,095 & 750,5 & 698,6 \\
\hline Água & 5,0 & 35,0 & 32,1 & 6,7 & & \\
\hline 1976 Solo & 0,018 & 0,076 & 0,045 & 0,020 & 634,6 & 592,0 \\
\hline Água & 4,0 & 9,0 & 4,8 & 4,4 & & \\
\hline 1977 Solo & 0,087 & 1,562 & 2,290 & 0,090 & $1.003,2$ & 972,3 \\
\hline Água & 8,4 & 36,5 & 10,9 & 10,5 & & \\
\hline 1978 Solo & 0,014 & 2,007 & 1,454 & 0,019 & 935,7 & 850,6 \\
\hline Água & 4,1 & 16,7 & 11,6 & 4,6 & & \\
\hline 1979 Solo & 0,015 & 0,016 & 0,023 & 0,016 & 466,0 & 401,0 \\
\hline Água & 2,3 & 3,6 & 3,9 & 4,5 & & \\
\hline 1980 Solo & 0,017 & 0,539 & 1,679 & 0,019 & 636,4 & 560,9 \\
\hline Água & 4,3 & 9,6 & 11,8 & 7,2 & & \\
\hline 1981 Solo & 0,173 & 3,223 & 4,233 & 1,082 & 683,6 & 582,1 \\
\hline Água & 8,4 & 55,9 & 65,8 & 36,3 & & \\
\hline 1982 Solo & 0,012 & 17,107 & 14,607 & 0,075 & 632,2 & 573,9 \\
\hline Água & 4,6 & 66,6 & 58,5 & 17,7 & & \\
\hline 1983 Solo & 0,010 & 0,015 & 0,015 & 0,014 & 582,2 & 469,0 \\
\hline Água & 4,6 & 6,4 & 7,9 & 6,7 & & \\
\hline 1984 Solo & 0,009 & 0,179 & 1,311 & 0,026 & 683,5 & 627,2 \\
\hline Água & 3,5 & 12,2 & 19,9 & 8,9 & & \\
\hline 1985 Solo & 1,175 & 0,732 & 14,207 & 0,311 & 939,2 & 858,8 \\
\hline Água & 16,0 & 20,2 & 49,0 & 15,7 & & \\
\hline 1986 Solo & 0,381 & 3,643 & 15,967 & 0,026 & 932,1 & 863,2 \\
\hline Água & 10,4 & 20,5 & 45,3 & 7,2 & & \\
\hline 1987 Solo & 0,044 & 0,027 & 2,522 & 0.013 & 548,6 & 455,2 \\
\hline Água & 6,4 & 8,1 & 21,7 & 5,7 & & \\
\hline 1988 Solo & 6,139 & 9,262 & 14,109 & 3,339 & 702,4 & 603,8 \\
\hline Água & 31,3 & 56,3 & 51,6 & 32,4 & & \\
\hline 1989 Solo & 1,417 & 5,823 & 5,790 & 1,138 & 868,6 & 764,9 \\
\hline Água & 26,2 & 71,8 & 71,7 & 28,0 & & \\
\hline 1990 Solo & 0,004 & 0,012 & 0,028 & 0,009 & 592,7 & 483,2 \\
\hline Água & 4,9 & 8,1 & 9,9 & 6,7 & & \\
\hline Total acumulado & & & & & $15.228,3$ & $13.659,7$ \\
\hline Solo & 10,978 & 46,593 & 81,231 & 7,007 & & \\
\hline Água & 206,8 & 517,0 & 535,8 & 262,9 & & \\
\hline Média ponderada & & & & & $725,2^{2}$ & $650,5^{3}$ \\
\hline Solo & 0,523 & 2,219 & 3,868 & 0,334 & & \\
\hline Água & 9,8 & 24,6 & 25,5 & 12,5 & & \\
\hline$\%$ chuva escorrida & 1,3 & 3,4 & 3,5 & 1,7 & & \\
\hline
\end{tabular}


(1981), que, em experimentos semelhantes, constataram perdas por erosão proporcionais à intensidade de mobilização do solo. Os diversos sistemas de mobilização afetam o processo erosivo diferentemente. Os dados mostram que a menor mobilização (EN e GR - gradagem) reduziu as perdas por erosão, pela menor desagregação das partículas por ocasião do preparo e pela presença de restos de vegetação que não foram totalmente incorporados. Alves et al. (1995) observaram que a persistência dos resíduos culturais de milho e soja sobre o solo, reduzindo o impacto direto das gotas de chuva, foi de fundamental importância para a redução da erosão hídrica.

Observou-se no tratamento $2 \mathrm{AG}$ uma perda média de solo $74 \%$ superior ao tratamento $A G$ (Tabela 2). No 2AG, a primeira aração foi sempre feita com um a dois meses de antecedência em relação ao preparo do solo dos demais tratamentos, como fazem, de modo geral, os agricultores do Agreste pernambucano, que preparam o solo por ocasião das chuvas de verão (fevereiro ou março) e plantam em abril ou maio. Portanto, a superfície do solo fica exposta à ação erosiva das gotas de chuva por mais tempo e apresenta uma condição extremamente favorável à erosão, como foi comprovado pelos resultados de perda de solo no 2AG. Segundo Margolis et al. (1985b), na região de Caruaru (PE), as chuvas mais erosivas ocorrem nos meses de fevereiro e março. Dessa forma, deve-se manter a superfície do solo coberta no período. Essa primeira aração acelera o processo erosivo e deve ser evitada.

As perdas médias anuais de solo e água foram pequenas (Tabela 2), mesmo nos tratamentos mais mobilizados $(2 \mathrm{AG}=3,868 \mathrm{t} / \mathrm{ha} /$ ano e $25,5 \mathrm{~mm} \mathrm{e}$ $\mathrm{AG}=2,219 \mathrm{t} / \mathrm{ha} /$ ano e $24,6 \mathrm{~mm}$ ). Foram muito baixas nos tratamentos menos mobilizados $(\mathrm{EN}=0,523 \mathrm{t} / \mathrm{ha} /$ ano e $9,8 \mathrm{~mm}$ e $\mathrm{GR}=0,334 \mathrm{t} / \mathrm{ha} /$ ano e $12,5 \mathrm{~mm}$ ), e não atingiram o limite máximo tolerável de perdas de solo que, de acordo com Bertoni \& Lombardi Neto (1985), para os Regossolos do Estado de São Paulo, varia de 9,7 a 16,5 t/ha/ano. Os autores afirmam que, segundo a FAO (1967), perdas de $12,5 \mathrm{t}$ /ha/ano são toleráveis para solos profundos, e que perdas de 2, 0 a 4,0 t/ha/ano são admissíveis em solos com subsolo desfavorável e pouco profundo, e que em solo Litólico, a tolerância às perdas por erosão está entre 1,9 e 7,3 t/ha/ano.
Em todos os tratamentos testados neste trabalho, as perdas médias anuais de solo estiveram abaixo de 4,0 t/ha/ano, portanto, dentro do limite de tolerância para solos pouco profundos. As pequenas perdas de solo e água verificadas podem também ser atribuídas à grande quantidade de cascalho e areia neles existente (Tabela 1). A areia grossa concentrada na superfície, em virtude da remoção de partículas mais finas, exerce efeito amortecedor muito pronunciado ao impacto das gotas de chuvas, tornando-as menos erosivas, além de formar um "mulch" natural, favorecendo a infiltração da água de chuva, conforme pode ser verificado pelos dados de percentagem de chuva escorrida (Tabela 2), que em todos os tratamentos foram muito baixos. A ausência de camadas pouco permeáveis próximas à superfície, a grande infiltração de água e a encrostação superficial pouco pronunciada, em razão da presença de partículas grosseiras, contribuem para tornar esses ambientes mais conservadores, com um fator $\mathrm{k}$ (erodibilidade do solo) muito baixo. Encontrou-se para o solo em questão um valor k de 0,08 (Margolis et al., 1985a), classificado como de suscetibilidade à erosão de fraca a nula (Leprun, 1981).

As perdas de solo e água podem ainda ser mais reduzidas, se faixas de vegetação permanente forem adotadas. De acordo com Margolis et al. (1985b), a utilização de faixas em contorno (2,0 m de largura, com espaçamento de 13,5 m entre elas) de capim sempre-verde (Panicum maximum Jacq.), em solo com declividade de $12 \%$, arado, gradeado e cultivado anualmente com milho, foi capaz de reduzir as perdas de solo e água em $86,6 \%$ e $58,5 \%$, respectivamente, quando comparada com a prática de plantio em contorno.

Observando-se as produtividades de milho e feijão no período de 1977 a 1986 (Tabela 3), foram verificadas variações entre os mesmos tratamentos, isso em virtude da distribuição irregular das chuvas no período de cultivo. As produtividades dos diversos tratamentos no mesmo ano também foram variáveis, e, de modo geral, os mobilizados mais intensamente (2AG e AG) proporcionaram maiores produtividades que os demais, principalmente em relação à cultura do milho. Resultados semelhantes foram obtidos por Browning \& Norton (1945) e Marques \& Bertoni (1961), que conseguiram produções mais ele-

Pesq. agropec. bras., Brasília, v.34, n.2, p.299-307, fev. 1999 


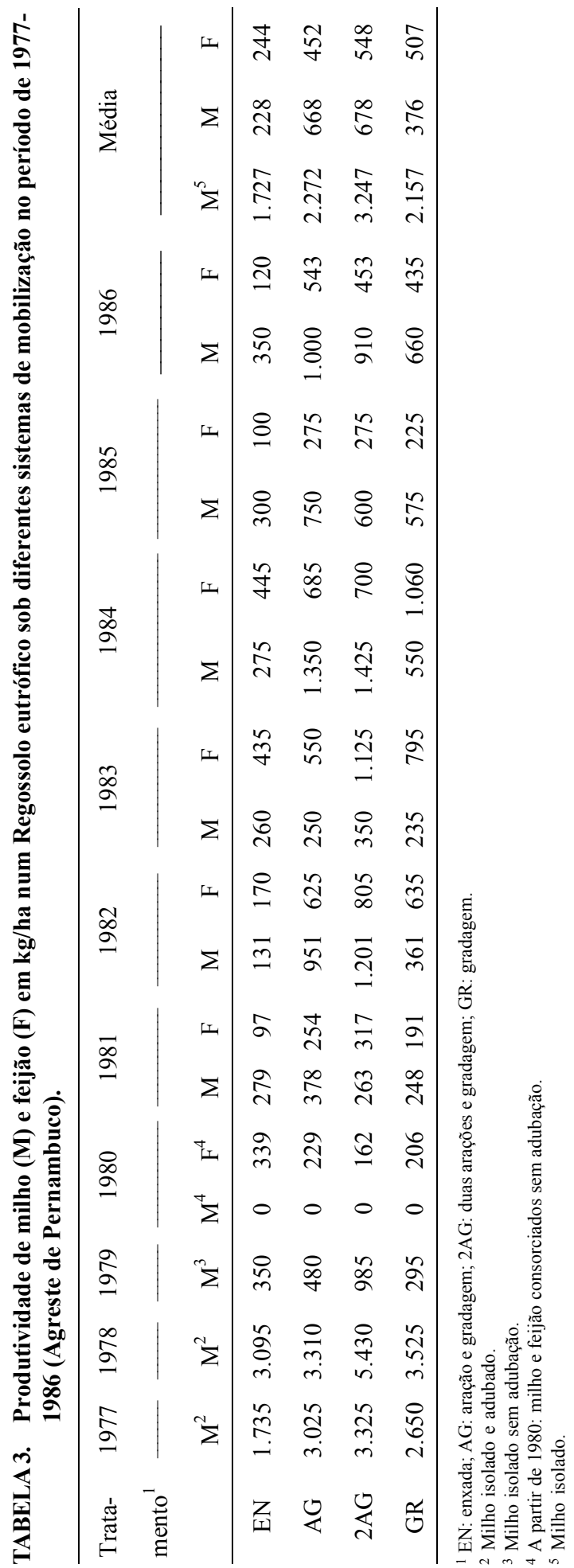

vadas no preparo do solo com revolvimento. A partir de 1980, o milho e o feijão passaram a ser cultivados em consórcio sem adubação. A produção do milho caiu muito por causa da ausência de adubação, fato também observado por Zaffaroni et al. (1991). Pelos resultados de produtividades médias de milho e feijão consorciados sem adubação (Tabela 3), verificados nos tratamentos $2 \mathrm{AG}$ e $\mathrm{AG}$, que foram muito semelhantes, desaconselha-se a realização da primeira aração nas primeiras chuvas, uma vez que ela apenas intensifica as perdas de solo, como foi verificado anteriormente ( $74 \%$ superior ao tratamento $\mathrm{AG}$ ).

Para explicar as diferenças nas produtividades médias de milho e feijão, procurou-se analisar a disponibilidade dos nutrientes em profundidade nos diversos tratamentos, o que permitiu verificar teores mínimos de $\mathrm{Ca}^{2+}$ nas profundidades de 10 a $19 \mathrm{~cm}$ (Silva, 1986). Isso parece indicar que a maior taxa de absorção de nutrientes ocorre nessa profundidade, já que os primeiros centímetros constituem-se na camada de solo mais estressante, quando o solo está descoberto (Russell, 1973; Medeiros, 1977; Resende, 1983). A evaporação na região em estudo proporciona perda muito elevada de água dos primeiros centímetros, e nos solos arenosos, nos quais predomina areia grossa, a água disponível encontra-se na subsuperfície. Portanto, os tratamentos que colocam as camadas mais ricas em nutrientes a profundidades maiores tendem a facilitar a absorção de nutrientes e, em conseqüência, elevar a produção (2AG e AG).

Os teores médios de $\mathrm{P}$ (Mehlich-1), determinados nas profundidades $9-14 \mathrm{~cm}, 10-19 \mathrm{~cm}, 14-22 \mathrm{~cm}$ e $22-40 \mathrm{~cm}$, correlacionaram-se melhor com a produtividade média do milho e do feijão, respectivamente, do que os teores médios determinados nos primeiros $10 \mathrm{~cm}$, e mesmo com a média dos primeiros $22 \mathrm{~cm}$ (Tabela 4). Como o P é considerado o nutriente menos disponível no ecossistema, em virtude da pequena ocorrência de minerais fontes (Brasil, 1972; Mafra, 1981), os sistemas de manejo que incorporam o $\mathrm{P}$ a maiores profundidades, onde a umidade mais elevada favorece a taxa de difusão do $\mathrm{P}$ até as raízes (Ruiz, 1986), tendem a apresentar as melhores produções. 
TABELA4. Teores médios de fósforo (Mehlich-1) em várias profundidades e valores dos coeficientes de correlação (r) com a produtividade média do milho isolado $\left(Y_{1}\right)$, consorciado com feijão $\left(Y_{2}\right)$ e feijão consorciado com milho $\left(\mathrm{Y}_{3}\right)$, em um Regossolo eutrófico do Agreste de Pernambuco, submetido a diferentes sistemas de manejo.

\begin{tabular}{|c|c|c|c|c|c|c|c|}
\hline \multirow[t]{2}{*}{ Profundidade } & \multicolumn{4}{|c|}{ Tratamentos $^{1}$} & \multicolumn{3}{|c|}{$\mathrm{r}$} \\
\hline & EN & $\mathrm{AG}$ & $2 \mathrm{AG}$ & GR & $\mathrm{Y}_{1}$ & $\mathrm{Y}_{2}$ & $\mathrm{Y}_{3}$ \\
\hline$(\mathrm{cm})$ & \multicolumn{7}{|c|}{----------------P (mg/dm³)----------------- } \\
\hline $0-3$ & 78 & 36 & 59 & 68 & $-0,34^{\mathrm{ns}}$ & $-0,84^{\mathrm{ns}}$ & $-0,47^{\mathrm{n}}$ \\
\hline $3-6$ & 63 & 36 & 44 & 46 & $-0,53^{\mathrm{ns}}$ & $-0,87^{\mathrm{ns}}$ & $-0,79^{\mathrm{n}}$ \\
\hline $6-9$ & 50 & 30 & 37 & 32 & $-0,38^{\text {ns }}$ & $-0,68^{\text {ns }}$ & $-0,81^{\mathrm{n}}$ \\
\hline $9-14$ & 29 & 30 & 39 & 28 & $0,93^{*}$ & $0,65^{\text {ns }}$ & $0,51^{\mathrm{n}}$ \\
\hline $14-22$ & 13 & 30 & 32 & 18 & $0,83^{\text {ns }}$ & $0,99^{* *}$ & $0,72^{\mathrm{n}}$ \\
\hline $22-40$ & 05 & 07 & 09 & 10 & $0,57^{\text {ns }}$ & $0,38^{\text {ns }}$ & $0,91^{*}$ \\
\hline $0-10$ & 61 & 32 & 46 & 47 & $-0,37^{\text {ns }}$ & $-0,83^{\text {ns }}$ & $-0,63^{\mathrm{n}}$ \\
\hline $10-19$ & 19 & 31 & 38 & 22 & $0,93^{*}$ & $0,94^{*}$ & $0,70^{\mathrm{n}}$ \\
\hline $0-22$ & 47 & 32 & 42 & 38 & $-0,13^{\mathrm{ns}}$ & $-0,63^{\text {ns }}$ & $-0,54^{\mathrm{n}}$ \\
\hline $0-40$ & 40 & 20 & 37 & 34 & $0,003^{\mathrm{ns}}$ & $-0,59^{\text {ns }}$ & $-0,29^{n}$ \\
\hline
\end{tabular}

${ }^{1}$ EN: enxada; AG: aração e gradagem; 2AG: duas arações e gradagem; GR: gradagem.

* Significativo a $10 \%$ de probabilidade, pelo teste $\mathrm{t}$.

** Significativo a $1 \%$ de probabilidade, pelo teste $\mathrm{t}$

ns Não-significativo.

As análises para fins de fertilidade e a aplicação de fertilizantes para ecossistemas afins ao estudado devem concentrar a atenção nesta faixa mais crítica de $10-22 \mathrm{~cm}$.

\section{CONCLUSÕES}

1. Os tratamentos com maior intensidade de mobilização do solo favorecem a erosão; esta, no entanto, é em média muito baixa, devido às quantidades de cascalho e areia grossa existentes no perfil.

2. As produtividades médias de milho são maiores nos tratamentos mais mobilizados, e correlacionam-se com os teores médios de $\mathrm{P}$ (Mehlich-1) nas profundidades de 9 a $14 \mathrm{~cm}$, de 10 a $19 \mathrm{~cm}$ e de 14 a $22 \mathrm{~cm}$.

3. As produtividades médias de feijão são maiores nos tratamentos gradagem, aração e gradagem e duas arações e gradagem, e correlacionam-se com os teores médios de $\mathrm{P}$ (Mehlich-1) na profundidade de 22 a $40 \mathrm{~cm}$.

\section{REFERÊNCIAS}

ALBUQUERQUE, A.W. de; CHAVES, I.B. de; VASQUES FILHO, J. Características físicas da chuva correlacionadas com as perdas de solo num regossolo eutrófico de Caruaru (PE). Revista Brasileira de Ciência do Solo, v.18, p.279-283, 1994.

ALVES, A.G.C.; COGO, N.P.; LEVIEN, R. Relações da erosão do solo com a persistência da cobertura vegetal morta. Revista Brasileira de Ciência do Solo, v.19, p.127-132, 1995.

BARUQUI, F.M.; FERNANDES, M.R. Práticas de conservação do solo. Informe Agropecuário, Belo Horizonte, v.11, p.55-69, 1985.

BERTOL, I.; COGO, N.P.; LEVIEN, R. Comprimento crítico do declive em sistemas de preparos conservacionistas de solo. Revista Brasileira de Ciência do Solo, v.21, p.139-148, 1997.

BERTONI, J. Sistemas coletores para determinação de perdas por erosão. Bragantia, Campinas, v.9, p.147155, 1949.

Pesq. agropec. bras., Brasília, v.34, n.2, p.299-307, fev. 1999 
BERTONI, J.; LOMBARDI NETO, F. Conservação do solo. Piracicaba: Livroceres, 1985. 392p.

BERTONI, J.; LOMBARDI NETO, F.; BENATTI JUNIOR, R. Equação de perdas de solo. Campinas: IAC, 1975. 25p. (Boletim técnico, 21).

BISCAIA, R.C.M. Perdas de solo, em diferentes tipos de preparo para a sucessão soja-trigo, sob chuvas naturais. In: ENCONTRO NACIONAL DE PESQUISA EM CONSERVAÇÃO DO SOLO, 2., 1978, Passo Fundo. Anais... Passo Fundo: Embrapa-CNPT, 1978. p.237-246.

BRASIL. Ministério da Agricultura. Levantamento exploratório-reconhecimento de solos do Estado de Pernambuco. Recife, 1972. v.2, 354p. (Boletim técnico, 26).

BRASIL. Ministério da Agricultura. Levantamento exploratório-reconhecimento de solos do Estado de Pernambuco. Recife, 1973. v.1, 359p. (Boletim técnico, 26).

BROWNING, G.M.; NORTON, R.A. Tillage practices on selected soils in Iowa. Soil Science Society of America. Proceedings, v.10, p.461-468, 1945.

BROWNING, G.M.; NORTON, R.A. Tillage, structure, and irrigation: tillage practices with corn and soybeans in Iowa. Soil Science Society of America. Proceedings, v.12, p.491-496, 1947.

CANTALICE, J.R.B.; MARGOLIS, E. Características das chuvas e correlação de índices de erosividade com as perdas de solo do agreste de Pernambuco. Revista Brasileira de Ciência do Solo, v.17, p.275-281, 1993.

COGO, N.P. Uma contribuição a metodologia de estudo das perdas por erosão em condições de chuva natural: I. Sugestões gerais, medição do volume, amostragem e quantificação de solo e água da enxurrada (1 ${ }^{\text {a }}$ aprox.). In: ENCONTRO NACIONAL DE PESQUISA SOBRE CONSERVAÇÃO DO SOLO, 2., 1978, Passo Fundo. Anais... Passo Fundo: Embrapa-CNPT, 1978. p.75-97.

DEFELIPO, B.V.; RIBEIRO, A.C. Análise química do solo (metodologia). Viçosa: UFV, 1981. 17p. (UFV. Boletim de Extensão, 29).

DULEY, F.L.; RUSSEL, J.C. Effect of stubble mulching on soil erosion and runoff. Soil Science Society of America. Proceedings, v.7, p.77-81, 1942.
FAO. (Roma, Itália). La erosion del suelo por el água: algumas medidas para combatirla en las tierras de cultivo. Roma, 1967. 207p.

FREITAS, M.B. de; CHOUDHURY, E.N.; FARIA, C.M.B. de. Manejo e conservação de solo no agreste de Pernambuco. Petrolina, PE: EmbrapaCPATSA, 1981. 44p. (Embrapa-CPATSA. Boletim de Pesquisa, 6).

LEPRUN, J.C. A erosão, a conservação e o manejo do solo no Nordeste Brasileiro: balanço, diagnóstico e novas linhas de pesquisa. Recife: SUDENE-DRN, 1981. 106p. (Série: Brasil. SUDENE, Recursos de Solos, 15).

MAFRA, R.C. Agricultura de sequeiro no Trópico Semi-Árido: um delineamento para a ação da pesquisa. Recife: Secretaria de Agricultura de Pernambuco, 1981. 56p.

MARGOLIS, E.; ALBUQUERQUE, I.A. Observações preliminares sobre as perdas por erosão na Estação Experimental de Caruaru. Recife: IPA, 1971. 24p. (Boletim técnico, 51).

MARGOLIS, E.; MELLO NETTO, A.V. Observações gerais sobre as perdas por erosão na Zona do Agreste de Pernambuco. Recife: IPA, 1977. 19p. (Boletim técnico, 74).

MARGOLIS, E.; SILVA, A.B. da; JACQUES, F. de. O. Determinação dos fatores da equação universal das perdas de solo para as condições de Caruaru (PE). Revista Brasileira de Ciência do Solo, v.9, p.165-169, 1985a.

MARGOLIS, E.; SILVA, A.B. da; REIS, O.V. dos. Controle da erosão com diferentes práticas conservacionistas num solo Litólico de Caruaru (PE). Revista Brasileira de Ciência do Solo, v.9, p.161-164, 1985b.

MARQUES, J.Q.A.; BERTONI, J. Sistemas de preparo do solo em relação à produção e à erosão. Bragantia, Campinas, v.20, p.403-459, 1961.

MARQUES, J.Q.A.; BERTONI, J.; BARRETO, G.B. Perdas por erosão no Estado de São Paulo. Bragantia, Campinas, v.20, p.1143-1182, 1961.

MEDEIROS, L.A.R. Caracterização e gênese de solos derivados de calcário e de sedimentos terciários da Região de Jaíba, Norte de Minas Gerais. Viçosa: UFV, 1977. 107p. Tese de Mestrado. 
OLIVEIRA, E.F.; BAIRRÃO, J.F.M.; CARRARO, I.M.; BALBINO, L.C. Efeito do sistema de preparo do solo nas suas características físicas e químicas e no rendimento de trigo e soja em Latossolo Roxo. I. Resultados obtidos em 1982 a 1988. Cascavel: OCEPAR, 1990. 54p. (OCEPAR. Resultados de Pesquisa, 4).

RESENDE, M. Aplicações de conhecimentos pedológicos à conservação de solos. Informe Agropecuário, Belo Horizonte, v.11, p.3-18, 1985.

RESENDE, M. Bruno não cálcico: interpretação de um perfil. Mossoró: Fund. Guimarães Duque, 1983. 165p. (Coleção Mossoroense, 218).

RUIZ, H.A. Efeito do conteúdo de água sobre o transporte de fósforo em dois Latossolos. Viçosa: UFV, 1986. 86p. Tese de Doutorado.

RUSSELL, E.W. Soil conditions and plant growth. London: Longman, 1973. 849p.
SEGANFREDO, M.L.; ELTZ, F.L.F.; BRUN, A.C.R. Perdas de solo, água e nutrientes por erosão em sistemas de culturas em plantio direto. Revista Brasileira de Ciência do Solo, v.21, p.287-291, 1997.

SILVA, A.B. da. Caracterização dos principais solos do agreste de Pernambuco e o efeito do manejo de um Regossolo eutrófico sobre a erosão e produtividade de milho e feijão. Viçosa: UFV, 1986. 108p. Tese de Mestrado.

VILELLA, S.M.; MATTOS, A. Hidrologia aplicada. São Paulo: McGraw-Hill do Brasil, 1975. 245p.

WISCHMEIER, W.H.; SMITH, D.D. Predicting rainfall erosion losses - a guide to conservation planning. Washington, DC: USDA, 1978. 58p. (Agriculture Handbook, 537).

ZAFFARONI, E.; BARROS, H.H.A.; NÓBREGA, J.A.M.; LACERDA, J.T.; SOUZA JUNIOR, V.E. Efeito de métodos de preparo do solo na produtividade e outras características agronômicas de milho e feijão no Nordeste do Brasil. Revista Brasileira de Ciência do Solo, v.15, p.99-104, 1991. 